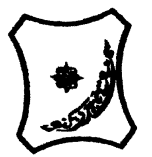

Bayero Journal of Pure and Applied Sciences, 10(1): 336 - 340

ISSN $2006-6996$

\title{
A PRELIMINARY STUDY OF SOIL FUNGAL DIVERSITY OF DYE-CONTAMINATED SOILS IN URBAN KANO
}

\author{
Sani, Z. M. ${ }^{*}$ and Abdullahi, I.L. \\ ${ }^{1}$ Department of Biological Sciences, Bayero University, Kano, Nigeria \\ *Corresponding author: zmsani.bio@buk.edu.ng
}

\section{ABSTRACT}

A wide variety of fungal species have been reported to survive in dye contaminated environments due to their ability to degrade and decolourize the dyes. This study is aimed at detecting the presence of fungal species capable of surviving in dye-contaminated soils, and also monitored their capability to decolourize these dyes. This was achieved using serial dilution and pour-plating methods. The result showed fungal growth in all the dye contaminated soil samples collected from the dyeing sites, Zawaciki had the highest fungal count $\left(6.30 \times 10^{3} \mathrm{cfu} / \mathrm{g}\right)$, followed by Kofar Na'isa $\left(1.27 \times 10^{3} \mathrm{cfu} / \mathrm{g}\right)$ and Kofar Mata $\left(1.20 \times 10^{2} \mathrm{cfu} / \mathrm{g}\right)$. Eight (8) species of fungi were identified (Aspergillus fumigatus, Aspergillus niger, Aspergillus ochraceus, Aspergillus parasiticus, Aspergillus terreus, Chrysosporium sp., Penicillium sp. and Trichoderma sp.), out of which three (Aspergillus niger, Aspergillus fumigatus, and Penicillium sp.) were common to the three sites.Aspergillus ochraceus was the only fungal species that was able to decolourize one of the four dyestested (i.e. blue dye), though, the decolourization was very weak. Further research on the possibility of these fungal species to biodegrade these dyes should be employed to reduce contamination.

Keywords: textile dyes, dyeing, fungi, decolourization and biodegradation.

\section{INTRODUCTION}

Dyes are introduced into the environment through industrial effluents from food, drug, cosmetic, textile and dyestuff factories which are discharged through drains and canals which flow directly into water bodies (rivers, sea, etc.) without treatment and purification (Rahman et al., 2009). The effluents from dyeing and textile industries contain chemicals with intense colours and the release of these effluents to receiving streams may be objectionable for various aesthetic reasons. A number of dyes and chemicals used by these textile industries are not degradable. Further, these coloured dye wastes contain compounds that are difficult to treat biologically due to their resistance against biodegradation (Suzuki et al., 2001). The excessive and indiscriminate use of these dyestuffs has become increasingly a subject of environmental concern. These dyes can enter the environment through the industrial effluents of dye manufacturing plants and from textile dyeing and printing operations, as wastewater effluents (Mathur, et al., 2005), which subsequently undergo chemical changes as well as biological changes in the aquatic system, consume dissolved Oxygen and thus disturb the aquatic ecosystem (Rahman et al., 2009). Survival of fishes and other lives becomes difficult and widespread. In the presence of these organic compounds, The textile processes and dyeing in particular requires substantial quantity of water and most water becomes unusable for practical and domestic uses. It is well known that dyes and degradation products are highly toxic, carcinogenic, and caused water pollution. It is therefore necessary to treat the water containing colour dyes and other organic compounds before discharging them (Rahman et al., 2009).

Due to the complex aromatic structure and stability of these dyes, conventional biological pre-treatment methods are ineffective for degradation (Rahman et al., 2009). They are thus a potent hazard to the natural sources like soil, water, flora, fauna, livestock and human population. Since large quantities of dyes are used, such pollution due to dyes may occur on a significant scale (Nupur et al., 2012).

In addition to the aforementioned problems, the textile industry consumes large amounts of potable and industrial water as processing water (90-94\%) and a relatively low percentage as cooling water (6-10\%) (in comparison with the chemical industry where only $20 \%$ is used as process water and the rest for cooling) (Baban et al., 2010). Another problem associated with these chemicals is their capacity to contaminate, cause harm and even damage or death to humans, animals, plants as well as other biotic systems over a period of time (Kumar et al., 2007). 
of it is subsequently returned in the form of wastewater or effluent and sludge (McKay, 1979).

In many places like Kano, the wastewater or effluents are not treated or re-processed to remove the harmful or toxic substances before being discharged into the environment. The parts of the environment that subsequently receives these effluents are the land (soils) and aquatic systems (lakes, rivers, ponds, streams, etc.). Living organisms are susceptible to the effects of these substances depending on their structure complexities and metabolic efficiency.

The increasing spread of secondary dyeing processing activities in urban Kano is causing some concern to the population. Similarly, the impact of the discharged effluents from this activity on land (soil) organisms, aquatic flora and fauna (species, composition, distribution and diversity), public health and environmental safety at present and in the immediate future needs to be given due consideration (Yusuff and
Sonibare, 2004). The present work is aimed at detecting the presence of fungal species capable of surviving in dye-contaminated soils, and also monitored their capability to decolourize these dyes.

\section{MATERIALS AND METHODS}

\section{Study Area}

Urban Kano is located at the central western part of Kano State between latitude $11^{\circ} 59^{\prime} 59.57^{\circ}-12^{\circ} 02^{\prime} 39.57^{\circ} \mathrm{N}$ of the equator and between longitudes $8^{\circ} 33^{\prime} 19.69^{\circ}$

$8^{\circ} 31^{\prime} 59.69^{\circ} \mathrm{E}$ and it covers an area of $137 \mathrm{sq} . \mathrm{km}$ (Oseiki, 2009).

A survey of the sites where this activity takes place was conducted using a GPS device $(12$ model - Garmin, USA) and the geographical coordinates were transferred onto a digital map of Kano to produce a map showing the specific selected sites of these dyeing processes (figure 1).

Sampling sites includes the Kofar Mata, Kofar $\mathrm{Na}$ 'isa and Zawaciki (Panshekara) dyeing pits.

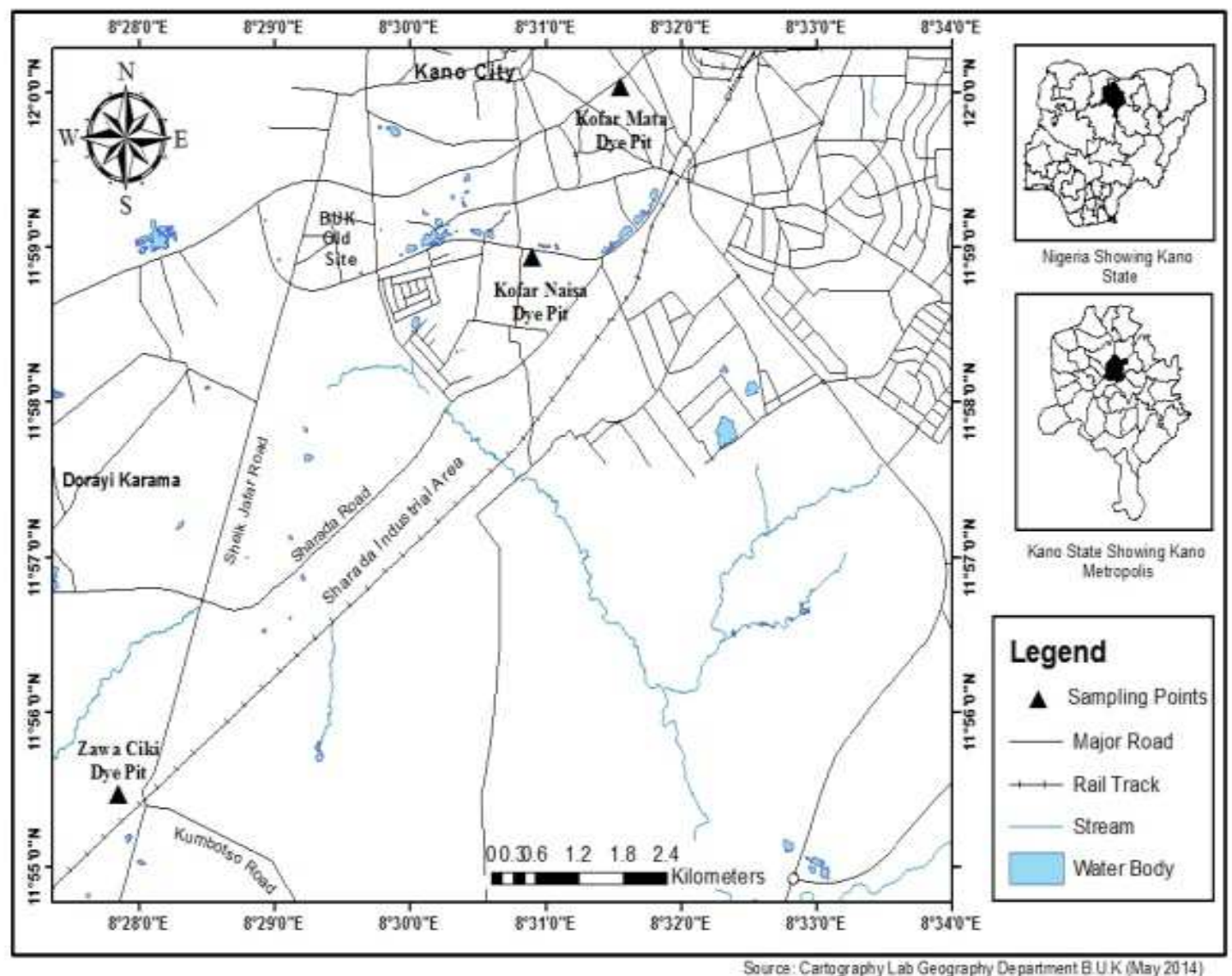

Figure 1: Map of Kano city showing the three dyeing activity sites; Kofar Mata, Kofar Na'isa and Zawaciki. 
Collection of contaminated soil samples

A garden shovel was used to dig the soil samples $(10 \mathrm{~cm}$ depth) at the dyeing sites (Ademoroti, 1996); these were subsequently transferred into a polythene bag for conveyance to Biological Sciences laboratory, Bayero University, Kano.

\section{Isolation of fungi}

The fungal species were isolated according to the method described by Philip (1982). This method involves the isolation of fungi using the Pour-plating technique after serial dilution of the contaminated soil sample onto PDA medium. The inoculated dishes were inverted and incubated at room temperature for five days. Fungal count and identification were done after five days. Results were recorded and expressed as cfu/g of soil (Benson, 1994).

Identification of Fungi

Fungal species obtained were identified based on their morphological appearance through visual observation and microscopy ( $\times 40$ objective), which was verified using an identification guide (Raper and Fennell, 1965). Five day old fungal isolates obtained were further sub-cultured on PDA medium containing individual dyes (four different dyes; blue, orange, red and yellow) and incubated in the dark at room temperature. Un-inoculated plates with the respective dyes were used as control. Isolates were prepared in duplicates. Plates were regularly monitored and observed for visual disappearance of colour for a period of 21 days (modified method of Nguietal., 2013).

Results

The results for fungal species identified from dye contaminated soils collected from three dyeing sites are presented in Tables 1 and 2 . Table 1 shows the fungal load for the contaminated soil samples from the three dyeing sites (Kofar Mata, Kofar $\mathrm{Na}$ 'isa and Zawaciki). Zawaciki had the highest fungal count $\left(6.30 \times 10^{3} \mathrm{cfu}\right)$, Kofar Na'isa $\left(1.27 \times 10^{3} \mathrm{cfu}\right)$ and then, Kofar Mata $\left(1.20 \times 10^{2} \mathrm{cfu}\right)$ having the least count. Table 2, shows the fungal occurrence in the dye-contaminated soils. A total of eight fungal species were identified from the dye contaminated soil samples, these include; Aspergillus niger, A. fumigatus, $A$. parasiticus, A. ochraceus, A. terreus, Penicillium sp., Trichoderma sp., and Chrysosporium sp., of which three (3) species (Aspergillus niger, A. fumigatus and Penicillium sp.) were isolated from all the contaminated soil samples from the three sites.

Table 1: Fungal Load for Dye-contaminated Soils of Three Selected Dyeing Sites in Kano

\begin{tabular}{lc}
\hline Sites & Fungal Count (cfu/g) \\
\hline Kofar Mata & $1.20 \times 10^{2}$ \\
KofarNa'isa & $1.27 \times 10^{3}$ \\
Zawaciki & $6.30 \times 10^{3}$ \\
\hline
\end{tabular}

Table 2: Frequency of Fungal Isolates in Dye-contaminated Soil Samples of Three selectedDyeingSites in Kano.

\begin{tabular}{lllll}
\hline Fungal Species & \multicolumn{2}{l}{ Sampling sites } & \\
\hline & KofarMata & KofarNa'isa & Zawaciki & Total (\%) \\
\hline Aspergillus fumigatus & + & + & + & $3(18.8)$ \\
Aspergillus niger & + & + & + & $3(18.8)$ \\
Aspergillus ochraceus & - & + & + & $2(12.5)$ \\
Aspergillus parasiticus & - & + & + & $2(12.5)$ \\
Aspergillus terreus & - & - & + & $1(6.3)$ \\
Chrysosporium sp. & - & - & + & $1(6.3)$ \\
Pennicillium sp. & + & + & + & $3(18.8)$ \\
Trichoderma sp. & - & - & + & $1(6.3)$ \\
\hline
\end{tabular}

Key

'+' = indicates presence of fungi

'. = indicates absence of fungi 
Plate 1 shows the changes that occurred in the macroscopic appearance of Trichoderma sp. after five days of inoculation on Potato dextrose agar dye medium. All the three
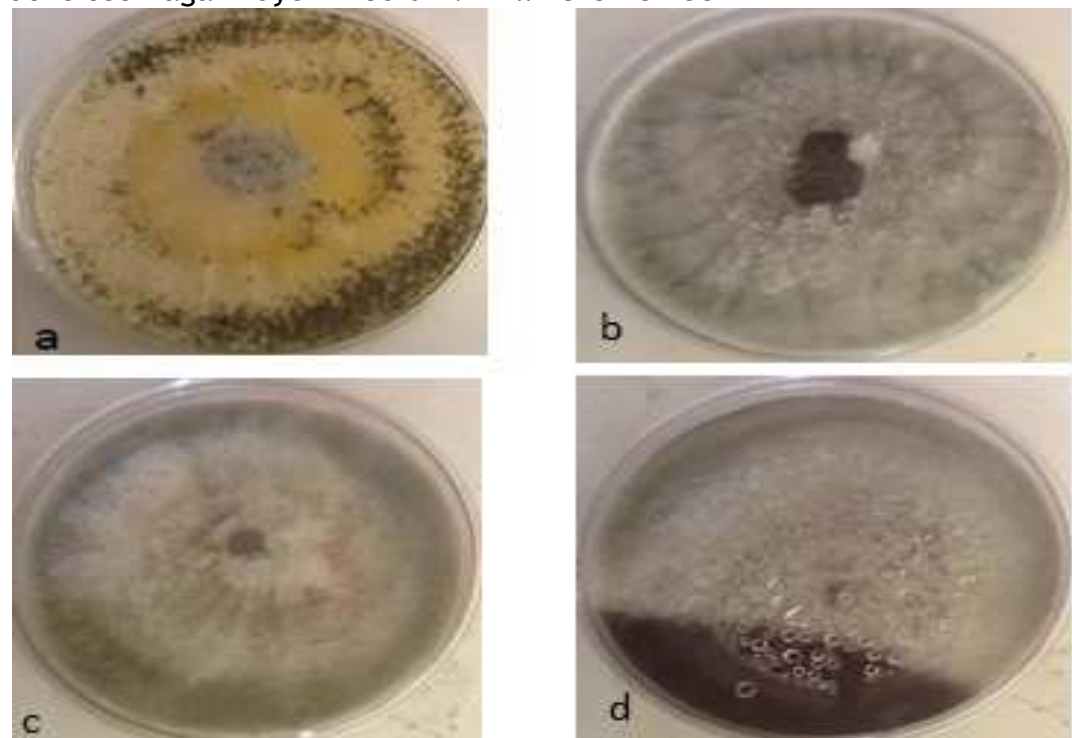

Plate 1, (a) Trichoderma inoculate, (b)Trichoderma sp. on blue dye medium, (c) Trichoderma sp. on orange dye medium, and (d) Trichoderma sp. on red dye medium.

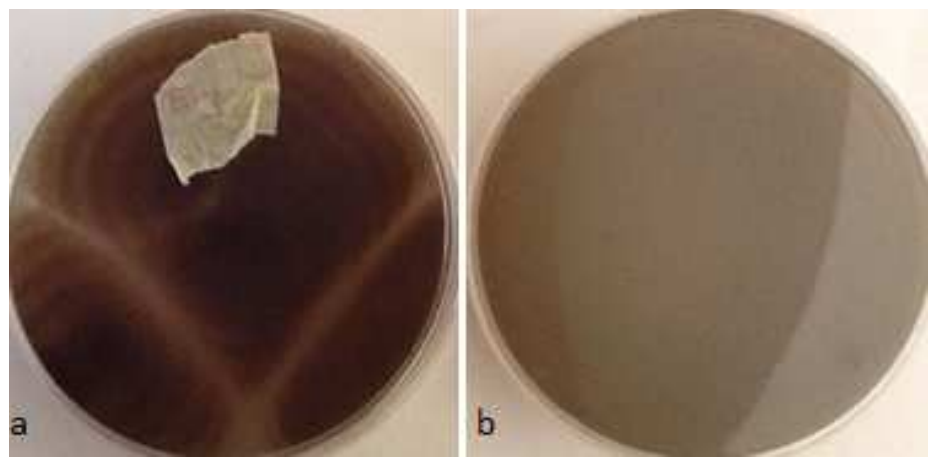

Plate 2, (a) Reverse side of the plate containing blue dye medium onto which Aspergillus ochraceus was inoculated indicating a faint decolourization after 21days of inoculation. (b) Plate containing blue dye medium with no inoculate (control).

\section{DISCUSSION}

In this research eight species of fungi were identified with Zawaciki having the highest load. This may be due to the discharge of the dye wastewater into an artificial stagnated reservoir where there is less mixing of the wastewater, thus, leading to a higher fungal load. Kofar Mata and Kofar Na'isa discharge their dye wastewater in local drains and channels where there is high mixing with runoffs and wastewaters from other domestic activities. The presence of these fungal species may be due to their ability to biosorb or biodegrade the dyes (Chen et al., 2003). Phanerochaete chrysosporium, a white-rot fungus, was reported by Reddy (1995) to be capable of degrading dioxins, polychlorinated biphenyls (PCBs) and other chloro-organics. Other fungal species such as Umbelopsisi sabellina, Penicillium geastrivous (Yang et al., 2003), Aspergillus foetidus and Rhizopus oryzae (Polman and Breckenridge, 1996), were also reported to have the ability to decolourize and/or biosorb diverse dyes. All the inoculated fungi grew successfully on the dyed PDA medium, signifying that they are capable of metabolizing the dyes. This may be due to the presence of various substances like acids, alkalis, salts or metal ions as impurities influencing the dye degrading capacity of the fungi (Kaushik and Malik, 2009). The weak decolourization observed agreed with the findings of Tisma et al. (2012), where they used Aspergillus ochraceus to decolourize four different textile dyes (methylene blue, congo red, violet and green dyes), which gave a positive result. Several researches suggest that Aspergillus spp., could be used to remove toxic 
and radioactive metals from the environment (Baker, 2006). This is because of their ability to decolourize and/or biosorb dyes and metals via the macromolecules in their mycelia wall (Fu and Viraraghavan, 2001). Joel and Roseline (2013) also reported Aspergillus species to have the potential to effectively decolourize

\section{REFERENCES}

Ademoroti, C.M.A. (1996): Environmental Chemistry and Toxicology, Foluder Press Itd Ibadan.

Baban, A., Yediler, A. and Ciliz, N.K. (2010): Integrated water management and CP implementation for wool and textile blend processes. Clean, 38(1): 84-90.

Baker, S.E. (2006): Aspergillus niger genomics: past, present and into the future. Medical Mycology, 44: 517-521.

Benson, H.J. (1994): Microbiological Applications, seventh edition: Laboratory manual in general microbiology, McGrawHill

Chen, K.C., Wu, J.Y., Liou, D.J. and Hwang S.C.J. (2003): Decolourization of the textile dyes by newly isolated bacterial strains. J. Biotechnol., 101: 57-68.

Fu, Y. and Viraraghavan, T. (2001): Fungal decolourization of dye wastewaters: a review. Bioresource Technology, 79(3): 251-262.

Joel, G.J. and Roseline, J.G. (2013): Decolourization of synthetic dyes using free and immobilized Aspergillus species. Research in Biotechnology, 4(5): 20-23.

Kaushik, P. and Malik, A. (2009): Fungal dye decolourization: recent advances and future potential. Environmental International Journal, 35: 127-141.

Kumar, P., Prasad, B., Mishra, I.M. and Chand, S. (2007): Catalytic thermal treatment of desizing wastewater. Hazardous Material, 149: 26-34.

Mathur, N., Bhatnagar, P. andBakre, P. (2005): Assessing Mutagenicity of textile dyes from Pali (Rajasthan) using Ames Bioassay. Applied Ecology and Environmental Research4(1): 111-118.

McKay, G. (1979): Waste Colour Removal from Textile Effluents. American Dyestuff. Rep. 68: 29-36.

Ngui, S.N., Azham, Z., Hairul, A.R. and Ahmad, H. (2013): Decolourisation of synthetic dyes by endophytic fungal flora isolated from senduduk plant (Melastoma malabathricum). Hindawi Publishing Corporation, ISRN Biotechnology, 1-8.

Nupur, M., Pradeep, B. and Pratibha, S. (2012): Review of the Mutagenicity of Textile Dye synthetic dyes due to biosorption of free and immobilized biomass.

\section{CONCLUSION}

In conclusion, the result of the study indicated that fungal species are capable of surviving in dye-contaminated environments, with some species being able to decolourize and/or biodegrade the dyes.

Products. Universal Journal of Environmental Research and Technology, 2(2): 1-18.

Oseiki, A.O. (2009): The influence of gender on intra-urban transportation. A case study of Kano metropolis. Unpublished undergraduate thesis submitted to Department of Geography, Ahmadu Bello University, Zaria.

Phillip, B.M. (1982): Consultants US food and drug administration, UNDP/FAO/THA/82/004. Reduction of postharvest losses in stored grains.

Polman, J.K. and Breckenridge, C.R. (1996): Biomass-mediated binding and recovery of textile dyes from waste effluents. Textile Chemist andColourist, 28(4): 31-35.

Rahman, M.M., Hasnat, M.A. and Kazuaki, S. (2009): Degradation of Commercial Textile Dye by Fenton's Reagent under Xenon Beam Irradiation in Aqueous Medium. J. Sci. Res. 1(1): 108-120

Raper, K.B. and Fennell, D.I. (1965): The Genus Aspergillus, Williams and Wilkins, Baltimore. 1-686.

Reddy, C.A. (1995): The potential for white-rot fungi in the treatment of pollutants. Curr. Opt. Biotechnol., 6: 320-328.

Suzuki, T., Tinolei, S., Kurunczi, L., Dietze, U. and Schuuirmann, G. (2001): Correlation of Aerobic Biodegradability of Sulfonated Azo dyes with the Chemical structure. Chemosphere, 45: 1-9.

Tisma, M., Komar, M., Rajic, M., Pavlovic H. and Zelic, B. (2012): Decolorization of dyes by Aspergillus ochraceus cultivated under solid state fermentation on sugar beet waste, Chemical Engineering Transactions, 27: 145-150.

Yang, Q., Yang, M., Pritsch, K., Yediler, A. and Kettrup, A. (2003): Decolourization of synthetic dyes and production of manganese-dependent peroxidiase by new fungal isolates. Biotechnology Letters, 25: 709-713.

Yusuff, R.O. and Sonibare, J.A. (2004): Characterization of Textile Industries' Effluents in Kaduna, Nigeria and Pollution Implications. Global Nest: the Int. J.,6(3): 212-221. 